\title{
An analysis on the Status of Harbin Summer Music Concert in Chinese Modern Music History
}

\author{
Yong Lu \\ College of Music, Hubei Engineering University, Xiaogan, 432000, China
}

Keywords: Harbin Summer Music Concert, Music festival, Music culture, Music history

\begin{abstract}
Harbin Summer Music Concert, Shanghai Spring Music Concert and Yangcheng Music Flower Fair are three main music festivals in China. Harbin Summer Music Concert began in Aug, 1961. Until now it has been held for 31 times. It not only makes great influence on the domestic music field, but also becomes a link for domestic and foreign cultural communication. It keeps inheriting and promoting Chinese traditional culture, and it develops with the time. Eventually Harbin Summer Music Concert becomes a famous national music brand. This paper analyses the achievement, influence, and characteristics of Harbin Summer music concert of different periods and concludes its status in Chinese modern music history.
\end{abstract}

\section{The development of Harbin Summer Music Concert}

"China· Harbin Summer Music Concert", is called Harbin Summer Music Concert for short. Harbin Summer Music Concert, Shanghai Spring Music Concert and Yangcheng Music Flower Fair are three main music festivals in China. Harbin is Located in the north of China. She is a city with specific cultural traditions. In the early days with amounts of immigrants swarming into Harbin, Western music culture followed in, too. Russian music culture had a great influence on the city. Liu Kewei once said: "The profound and lasting-oriented Russian music culture influences every aspect of Harbin citizens' life which is the foundation of the successful conduction of Harbin Summer Music Concert”. In the mutual mingling of eastern and western cultures, the special aesthetics of music of Harbin people was created.

\section{The stage division of the development of Harbin Summer Music Concert}

Harbin Summer Music Concert is a national level, nationwide grand gathering of music art held by The Ministry of Culture and Harbin Municipal government. It is one of the two music festivals with longest history and most times (The other one is Shanghai Spring International Music Festival). The development of Harbin Summer Music Concert can be mainly divided into three stages.

The first initial stage mainly includes mass culture activities. The time interval is from the first Harbin Summer Music Concert in 1961 to the $6^{\text {th }}$ Harbin Summer Music Concert in 1966. The Harbin Summer Music Concert in this period is mainly to enrich people's spare time culture life and to examine the achievements of mass culture activities.

The second stage is the combination of amateur and professional. The time interval is from the $7^{\text {th }}$ Harbin Summer Music Concert in 1979 to the $22^{\text {nd }}$ Harbin Summer Music Concert in 1994. This is the developing period of Harbin Summer Music Concert. The concerts in this period concentrate on elegant music with professional and communication, mass characteristic and universality. The concert attracted a lot of famous musicians and musical groups at home and abroad.

The third stage is the establishing of national level music culture brand. The time interval is from the $23^{\text {rd }}$ Harbin Summer Music Concert in 1996 to the $32^{\text {nd }}$ Harbin Summer Music Concert in 2014. Since the $23^{\text {rd }}$ concert, Harbin Summer Music Concert began to be held by the Ministry of culture and Harbin Municipal Government, thus Harbin Summer Music Concert steps into a brand new developing stage. National level, international direction and mass participation are guiding thoughts of Harbin Summer Music Concert. 


\section{The changes in the scales of Harbin Summer Music Concert}

The original purpose of Harbin Summer Music Concert was for local entertainment which had three breakthroughs. The first breakthrough was at the second term. The concert was held associated with Heilongjiang Province. At this term more than 430 tracks at home and abroad were performed on eight stages with impressive scales. The second breakthrough was at the $7^{\text {th }}$ term. The concert was held associated with Heilongjiang Province, Jilin Provence and Liaoning Provence. Though it was limited in the Northeast, its influence had already impacted all over the country. Many famous musicians such as Sheng Zhongguo, Qiu Li, Zhang quan, Luo tianchan were on invitation. On twenty five concerts more than 210 tracks were performed. The culture communications were original and new. Third breakthrough was at the $23^{\text {rd }}$ term. The concert was held associated with the Ministry of culture. The goal was to revive the refined art and create art boutiques. The National Vocal Music Competition and The National Opera Performance enhanced each other on Harbin Summer Music Concert. The conducting form of Harbin Summer Music Concert is becoming various; the program forms are enlarging; the number of programs is growing; the number of the audiences develops from thousands to ten thousands, And performers and staffs develops from dozens to hundreds even thousands. We can see the big change on the scale of Harbin Summer Music Concert.

\section{The changes of the items and features of Harbin Summer Music Concert}

Before the reform and opening up policy, Harbin Summer Music Concert completely carried out the policy of "All flowers bloom together. Contention of a hundred schools of thought" "Make the past serve the present, make foreign things serve China" "Get rid of the stale and bring forth the fresh". Harbin Summer Music Concert used to concentrate on classical music at home and abroad, vocal solo, instrumental music solo, ensemble, light music and drama. The tracks performed on the concert were usually about real life, or the revolutionary songs with strong militancy about people's beautiful life after the liberation. Since the reform and open up, various forms of foreign cultures swarmed in and enriched people's view and spare time life. Harbin Summer Music Concert comprehensively carries out the spirit of the third plenum, and chases after the four modernizations with full heart. Harbin Summer Music Concert adds singing and dancing performance and orchestra music on traditional performing forms which praises the wonderful life after the reform and opening up policy and the visions for future life. From the $21^{\text {st }}$ century, Harbin Municipal Party Committee and Harbin Municipal Government put forward the strategy policy of "Build the city on the culture". The importance of mass culture is significantly valued. As an important part of advanced socialist culture, Harbin Summer Music Concert adds popular music in the performance, and also introduces music programs as "the same song" to the concert which is strongly supported by the mass. National wide music activities go on the stage of the concert. On the $23{ }^{\text {rd }}$ Harbin Summer Music Concert There are opera watching performance and national vocal music competition. The concert is given with new vitality and new charms by internationalization, specialization and mass characteristic. It becomes a stage of the world, a festival for the people, a grand gathering of the music.

\section{The influence of Harbin Summer Music Concert}

\section{The influence of Harbin Summer Music Concert on musical education}

Harbin Summer Music Concert is held by Ministry of culture and Harbin Municipal government which has a great influence on the development of music culture education and makes a great contribution to the music culture education. In the early period, Harbin established Harbin Orchestra Music Association and music schools, instrumental stores and concerts. Especially the construction of Harbin Teachers College Art Academy is a major achievement. In the special performances in art colleges of the $25^{\text {th }}$ Harbin Summer Music Concert, the youth conduct of Harbin Teachers College, Fang Yunhai and Chinese American conductor Zhu Qiyuan and more than 80 students performed in the symphony. There are comprehensive music concert performed by all teachers and students, and vocal and instrumental music concerts performed by students with special dancing performances of Harbin Teachers College. 
In addition, since the $25^{\text {th }}$ Harbin Summer Music Concert, there are large scaled vocal music, instrumental music, and dancing competitions which attract dancing and music professionals in art institutes at home and abroad to participate in. The influence of Harbin Summer Music Concert is getting bigger and bigger. Furthermore, the prize winner players of the competitions in turn promote the development of music education. And the concert also invites famous musicians to perform and guide which has a demonstrated effect for the level and direction of the music concert.

These are the influences of Harbin Summer Music Concert on music education business. It promotes the development of music education of Harbin city. It even has influence on the national music education in a certain degree. Harbin Summer Music Concert enlarges the view of music fans. It points out the direction for the music education as diversification, specialization, and popularization to cultivate more professional talents for our country.

\section{The talent cultivation of Harbin Summer Music Concert}

The music education of Harbin has never been interrupted. Successively six regular music schools are established, which is the first batch of western music schools. They cultivated many music talents. The teachers in the schools are with high qualities and many of them are graduated from St. Petersburg, Kiev, Moscow, Paris, Milan and Leipzig music institutes. The music school carries out regular old type opera education and concentrates on artistic practice. It cultivates a lot of music talents for Harbin and the whole country. Now there are music institutes or music departments in the comprehensive universities such as Heilongjiang University and Harbin Normal University which contributes to the cultivation for the music talents. Harbin Summer Music Concert is the best platform to show the education achievement to these music institutes and more talents will be discovered and they can get self-affirmed and self-improved. The national vocal music competitions held by Harbin Summer Music Concert discovers a lot of brilliant music talents and famous singers as Zhang Quan, Guo Song, Li Guyi etc.

\section{The influence of Harbin Summer Music Concert on social trend}

Harbin Summer Music Concert has gone through more than 50 years. With people's enthusiastic participation, to people's favorite, it has become a feast of music culture for the people. And people inject the concert with more enthusiasm. Harbin Summer Music Concert shows its local feature, national customs and the image of the city for all the time. There are Korean folk custom percussion music performances, Children art special performance, Korean nationality traditional game activities. Harbin Summer Music Concert has been beyond the meaning for music and stage performance. This kind of folk custom activities helps to preserve the national culture, and promotes that national cultural communication. Harbin Summer Music Concert is not only a music feast, but a local traditional custom and music culture of Harbin. As one of the three main music concerts in China, Harbin Summer Music Concert is precedent of China's native music festival which leads the trend of native music festivals and shows its development vigor.

\section{Conclusion}

Harbin Summer Music Concert has gone through more than 50 years and it brings people with different music feast. Each time of breakthrough of each term stands for its success and glory. But in its process of development there are problems. Firstly, with the globalization, the purpose of Harbin Summer Music Concert concentrates on "economy on the stage of culture" since the $21^{\text {st }}$ term. The enterprises become the heroes of the stage. To chase for the maximization of economic interest, the purpose of Harbin Summer Music Concert is turning to commercial. The real mess cultural activities are becoming less and less. The math foundation is becoming weaker. Secondly, as a local music festival, Harbin Summer Music Concert is responsible for inheriting in and promoting the tradition of music art. It should set an example with more intense energy.

Branding with best quality is the only road for Harbin Summer Music Concert. The 25th Harbin Summer Music Concert Created an enormous effective broadcasting information space and gained effective advertising effect. With the help of Harbin News web, we can broadcast the concert easily. 
With the development of digital, information, Internet and other high technologies, it has been a common sense that digitization brings up informatization; informatization brings up industrialization; industrialization promotes social and economic development. The core concept of industrialization is the brand strategy. Harbin Summer Music Concert has to combine the era and people's requirement, tries its best to innovate so that the openness of Harbin Summer Music Concert can be improved.

\section{References}

[1] Zhang Hao. The overview of Harbin Summer Music Concert. North music. 2010.

[2] Gao Hong. The Era significance of Harbin Summer Music Concert. Art studies. 2012.

[3] Qiu Jinyu, Chen Xiaoguang. Look back at Harbin Summer Music Concert. Art studies. 2012.

[4] Harbin Daily: Create the brand of Harbin Summer Music Concert to make the city a famous music city.Harbin Daily.2008.

[5] Zhang Guocheng. 30 years of Harbin Summer Music Concert.Harbin: Harbin Press, 2012.

[6] Han xinan. Create a music logo of the city-Comment on 25th Harbin Summer Music Concert. People Music Press. 2000.

[7] Han Lulu. Harbin Summer Music Concert: Create a famous music city. Guangming Daily. 2013.

[8] Liu kewei. The reflection on Harbin Summer Music Concert. Art studies .2010.

[9] Liu sijia. Creat the official Weibo for Harbin Summer Music Concert.Jin Media Magazine. 2012.

[10]Wang Guang. Develop mass culture to enlarge Harbin Summer Music Concert. Professional Technology. 2013.

[11]Li Sha. The systematic study on the 25th Harbin Summer Music Concert with Internationalization, popularization, quality, and marketization. Art education.2014.

[12]Che Ning. The grand music gathering with the combination of art at home and abroad: the overview of the 27th Harbin Summer Music Concert. People Music Press. 2004. 